Bulletin UASVM Food Science and Technology 70(1)/2013, 1-7

ISSN-L 2344-2344; Print ISSN 2344-2344; Electronic ISSN 2344-5300

\title{
A Geographical and Historical Overview of the Transylvanian Cuisine
}

\author{
Adriana PĂUCEAN \\ University of Agricultural Sciences and Veterinary Medicine, Faculty of Food Science and \\ Technology,3-5 Mănăştur street, 3400, Cluj-Napoca, Romania \\ adriana.paucean@usamvcluj.ro
}

\begin{abstract}
The aim of this essay is to describe the Transylvanian cuisine, based on its historical and geographical characteristics, but also, deeply connected to all the other elements that have a thing to say in its definition. Therefore, we will be able to better understand the gastronomic culture in this area and its potential. Geographically speaking, the region in the Carpathian garden is characterized by mountains, meadows and especially hills. The variety of nature's forms, the moderate climate and the rich hydrographic network are defining elements to the vegetation and fauna of this place. The Transylvanian villages are filled with people who are deeply connected to the nature around them. Any visitor that connects with the daily life here can observe the big number of inland products obtained in personal farms or yards. A prosperous land reveals its numerous types of vegetable and fruit. A Christian nation for as long as it has existed, the Romanians use a variety of dishes at every Christian festal occasion. Therefore, the Orthodox Church has also influenced the culinary tradition in this area. Transylvania's specific cuisine has its special traits, but it is also influenced by other cultures, whose route somehow intersected with ours, such as: Hungarians, Saxons, Jewish people, Ukrainians or Slovaks. Another trait that needs to be mentioned is the fact that our alimentary tradition is deeply connected to the season we are in. After the body gets a lot of meat and fats during winter, it gets purified during spring and summer when more fruits and vegetables are consumed. The most common gastronomic techniques in the Transylvanian cuisine are: marinating, maturation, fumigation, salting- procedures that use the natural potential and eliminate the use of the chemical additives. In conclusion, we can consider the Transylvanian cuisine one of the most important parts of the multicultural heritage.
\end{abstract}

Keywords: Transylvanian Cuisine, culinary habits, gastronomic culture

\section{INTRODUCTION}

According to Romanian academician Sahleanu (1977), the elements which should be analyzed are: the uneven repartition of the quantity of aliments throughout the day; fats, vegetables, special condiments; the way meat is used, the dough, bread, sweet products, etc.

Firstly, we should emphasize the fact that food is not only an energy source. What we eat is deeply connected to things like: biology and biochemistry; physics and chemistry; anthropology, history, ecology, geography and sociology.

In this context, the Transylvanian cuisine represents an extension of the region characterized by variety and taste. People here usually eat in a balanced way and those who follow Christian rules, are capable of understanding why refraining from eating foods with animal provenience (before important holidays (Orthodox feasts), such as Christmas and Easter) is a good way to purify your body and soul.

On the other hand, we should not overlook the way the cuisine can affect tourism, by offering visitors the possibility to discover hidden treasures. A culture's cuisine is the first and very powerful description of its life and history. Gastronomy has always had a very important role in bringing cultures together. That is why a cookbook is a very good way to discover a 
group of people-a real trip through its intimacy and its civilization. And because hospitality is maybe the Romanians' most important trait, we should definitely discuss the value of gastronomic tourism in this area. An important Romanian writer and a lover of our traditional foods and wines (Teodoreanu, 2010) appreciated that "discovering a new type of food contributes more to human happiness than discovering a new star."

\section{GEOGRAPHICAL AND HISTORICAL LANDMARKS OF THE REGION}

By analyzing the name of this region in its both used forms- Transylvania or Ardealwe notice that these names are related to this region's geography: Transylvania named the country hidden among forests, while Ardeal is a place filled with hills. So, geographically speaking, the region in the Carpathian garden is characterized by mountains, meadows and especially hills (Fig. 1). The variety of nature's forms, the moderate climate and the rich hydrographic network are defining elements to the vegetation and fauna of this place. The Carpathians separate the temperate-continental Transylvanian plateau from the subMediterranean climate of southern and eastern Romania.

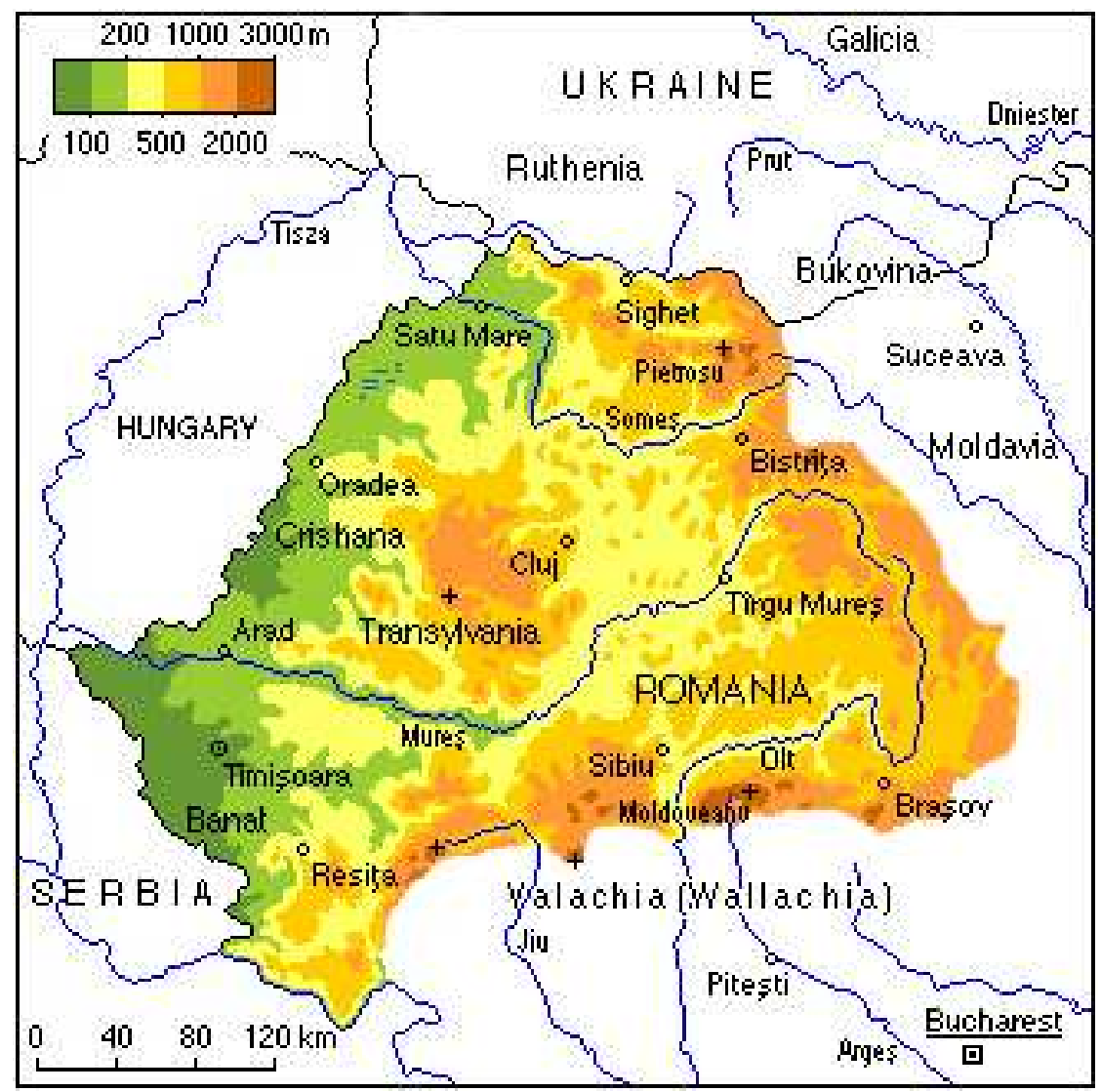

Fig 1. Transylvanian geographical map

(http://enciclopediaromaniei.ro/wiki/Transilvania)

Transylvania's specific cuisine has its special traits, but it is also influenced by other cultures, whose route somehow intersected with ours, such as: Hungarians, Saxons, Jewish people, Ukrainians or Slovaks. Referring to the medieval villages and to this countryside, Prince of Wales considered them as an irreplaceable fragment of natural and cultural heritage (Akeroyd, 2006). As a result of these intercultural exchanges, Transylvania has developed a variety of food culinary products in its villages. One of the most popular foods here is the 
"Pig leg bone with Sauerkraut" which is obtained after carrying out a complex process that aims to strengthen its organoleptic properties-its marinating helps us to tenderize the meat, while its special type of crust (which is still easy to masticate) appears as a result of its baking in a highly humid atmosphere. In the end, the use of annealed sauerkraut brings the final flavor to this food. There are numerous Hungarian types of food that have found their place in the Transylvanian cuisine, such as: Gulyás, Paprikás, Vargabéles, Szilvásgombóc, Szabógallér-leves, Tojásleves or even the tasty Kurtoskalacs.

I believe the following quote by our famous writer Petrescu (1970) is more than eloquent: "Us, the Romanians, have selected, have dosed, have perfected: the Hungarian papricaş, the Serbian haricot, the Polish butter and cream foods, the Russian marinades, caviar and the Turkish "musaca" and "Iman baialdi". We have never despised anything! We have never ignored anything! [...]. The cultures who know how to eat can't just pass through time without leaving traces!"

Due to this fact, we can consider the Transylvanian cuisine one of the most important parts of the multicultural heritage. Egon Ronay, an important British culinary critic with Hungarian origins, whose activity was manifested throughout the last half of the century, emphasized in his articles from the Daily Telegraph that three complex culinary concepts are to be always mentioned: the French one, the Chinese one and the Transylvanian one. Also, he mentioned several times a few types of Transylvanian traditional food: stuffed cabbage and pigs' trotters in aspic as of indescribable delicacy (Davidson, 1982).

Paul Kovi (1988) has written a monograph-like book on Transylvanian Cuisine. In this book he made interesting statements about the connection between Transylvanian and Chinese gastronomy. Few examples given by the author are:

- $\quad$ the utilization of ginger as spice

- The combinations between cabbages, pork are popular in both cuisines.

The Transylvanian villages are filled with people who are deeply connected to the nature around them. Both calm and sentimental, the Transylvanians are well known for their clean yards and for their rich meals which always have a dessert as a special treat. The Romanian cuisine consists of both daily foods and dishes created at special occasions (Suta, 1995). A Christian nation for as long as it has existed, the Romanians use a variety of dishes at every Christian festal occasion, traditional meals are served on holidays such as Christmas, Easter and New Year (Keppler, 2011). Therefore, the Orthodox Church has also influenced the culinary tradition in this area.

\section{TRANSYLVANIAN CULINARY HABITS}

In accordance with the Transylvanian culinary habits, the main meals are: breakfast, lunch and dinner. Breakfast can consist of dairy products, fresh cheese, bread, meats, boiled eggs, poached eggs, simple or more complex omelets, fresh fruits or jam.

Lunch usually combines three types of dishes:

- The soup- can consist of both vegetables and meat or only vegetables

- The main course- consists of meat, vegetables in various forms: stews, roast, sote

- $\quad$ The dessert- cakes, cookies, fruit, flans

At special occasions, we can find various appetizers, such as: vegetable salads, various types of sauce, pastries with meat/ cheese/ mushrooms.

Dinner usually consists of warm culinary dishes, but they are chosen so as to be easily digested. 
Furthermore, the Transylvanian cuisine can be analyzed by considering the differences between the culinary habits in urban and rural areas (Suta, 1995), as the society here was an agriculture-based one for a long period of time in the past. As a result, the entire culinary universe gravitated around agriculture and animal breeding- with a special accent put on sheep breeding. Any visitor that connects with the daily life here can observe the big number of inland products obtained in personal farms or yards. A prosperous land can actually brag about his "babies": potatoes, cereals, cabbage, tomatoes, cucumbers, various forms of pepper, pumpkins, eggplant and even numerous types of fruit. People who live in urban areas can find such products in special markets.

Another trait that needs to be mentioned is the fact that our alimentary tradition is deeply connected to the season we are in. Therefore, after the body gets a lot of meat and fats during winter, it gets purified during spring and summer when more fruits and vegetables are consumed.

The most common gastronomic techniques in the Transylvanian cuisine are: marinade, maturation, fumigation, salting- procedures that use the natural potential and eliminate the necessity to use chemical additives. We can also notice the fact that these dishes are made with patience, even though nowadays, the society is inclined to think that getting something done as quickly as possible is the ideal solution. Only by being patient and attentive while cooking, can we be able to maintain a link with what we eat, with the place food comes from and with the way aromas combine. This is why, one of the charismatic writer's Pastorel Teodoreanu aphorism is to be used nowadays: "There are many people who think that eating only implies having a stomach and money. They are wrong-you need a head, too."

\section{FOOD AND LOCAL PRODUCE}

Vegetables can be found in both fresh and preserved forms in various dishes, such as: soups, salads and other cooked dishes. Their seasoning is done using specific plants: estragon, dill, parsley, marjoram, lovage. The sauces that usually accompany the dishes are usually made from flour (with or without paprika) and sometimes sweetened with sugar.

Some examples would be:

- Cabbage-fresh or marinated in traditional dishes: "Cabbage á la Cluj"; "Cabbage rolls" or "Cabbage with smoked pig leg bone"

- Beans- green beans or brown beans are common in dishes like: "Beans and smoked bacon", "Bean soup with smoked meat", etc.

Sometimes, more vegetables put together become a special dish, such as the famous traditional "Zacusca" (also found in the Slavonic cuisine) obtained from eggplant, tomatoes and carrots in a complex process that is based on baking, roasting and boiling.

"Pickles" are also famous here, as a result of the lactic fermentation of cucumbers, green tomatoes, red peppers, etc. Some other pickles are obtained after adding a special solution based on vinegar and other plants, such as: horseradish, lovage, calamint, pepper or mustard beans, etc.

Cereals, as corn, wheat, rye, are the most common ones in alimentation. People in villages nowadays still hold the secret of the wheat-flour bread which is based on sourdough, raised using an lactic acidic fermentation, and which also respects the necessary proof duration in order to get valuable results concerning the aroma, the taste and both breadcrumb and crust structure. Other recipes include the potatoes, cornstarch or ray bread or even the famous "polenta" which is now known world widely. 
Another traditional food, usually eaten at Christmas or Easter, is called "Cozonac" and is made from high quality wheat flour and sometimes using nuts or poppy seeds.

Soups- make use of the vegetable potential and are an important part of the lunch menu. They are usually soured with sauerkraut liquid or green fruit purees.

Fruits are present in a wide variety of sorts, ranging from the ones that appear throughout summer to those from late autumn. Some of them are stashed and then consumed throughout winter, while others are preserved and then transformed into: jam, stewed fruit, marmalade, jellies, syrups, etc. Fruits are also found in soups (with smoked meat) or in sauces next to roasts. Sometimes, they are used to obtain delicious desserts, such as: "the apple and cinnamon pie" or "the plum and cinnamon dumplings".

Different sorts of dairy products are obtained as a result of the traditions we can find in this area, where people have always been concerned about sheep breeding. Besides the sheep milk, cow, buffalo cow or she-goat milk are also used here.

- Cheese assortments- "burduf cheese", "telemea" or simple cheese- are found in various dishes, such as: "cheese polenta", "cheese pasta", "whey mixed up with cow cheese", "pudding with sweet cheese pasta" (also known as Vargabeles)

- Cream- used in soups, sauces, etc.

- Yogurt/Kefir-usually consumed at breakfast or used as valuable additions to numerous types of dishes

Pig breeding is deeply connected to a traditional event that aims to sacrifice the pig a few weeks before Christmas. Here, several products are obtained, such as: "blood pudding", "sausages", "smoked bacon", "smoked fillet", "lard", etc.

Bird breeding- chickens, ducks, geese, turkeys - is often found with the aim to make use of their meat or their eggs. Some dishes in this category are: "Dumpling chicken soup"; "Rooster jelly" or "Turkey jelly".

We can also find various traditional recipes that reveal the secrets behind preparing beef or venison, showing different cooking methods, such as seasoning or hanging.

The apiculture provides us with various types of honey: locust honey, linden honey, mixed honey etc.

A good range of alcoholic and non-alcoholic drinks is available in the area, many of them home-made. Among the alcoholic ones, we should never overlook the "palinca" and "tuica", spirits made from plums and other fruits or sometimes from cereals, which is characterized by a high alcoholic concentration, double distillation and their boiling in a special caldron. These spirits are often offered on arrival at a home as a gesture of hospitality. Fruit are also used in beverages such as: cherry brandy or blueberry brandy and sometimes are regarded as lady's drink.

The wine culture is favored in this area because of the relief that seems to be destined for this activity, formed by numerous hills. The plateau of Transylvania, over $400 \mathrm{~m}$ above sea level and relatively cool and rainy, produces fresher and crisper white wines yhan those of the test of country. We are proud of the vineyards in the Târnava, Alba, Sebeş, Apold, Lechinţa-with their famous Blaj, Jidvei, Lechinta wines. Among the most appreciated white wines, we can name: "The White Feteasca", "The Royal Feteasca" or the delicious "Muscat Ottonel". Of the red grape varieties, "Babeasca" makes light fruity wines and Feteasca Neagra is a more "serious" with plenty taste wine.

The traditional nonalcoholic beverages- the elderflower juice, apple juice and other fruits juices, fruit tea or medicinal plant tea- are just some other examples of products that emphasize Transylvania's biological potential. 


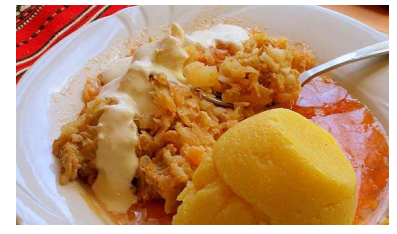

a-Cabbage á la Cluj

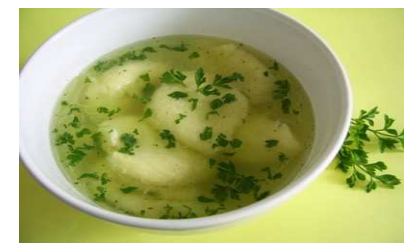

d- Chicken soup with dumplings

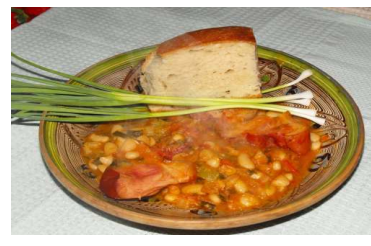

b- Beans and smoked bacon

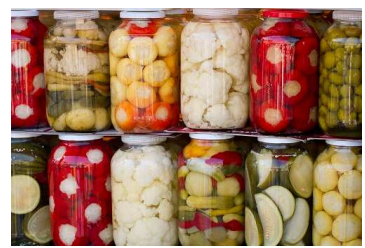

e- Pickles

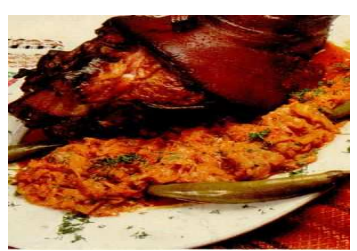

c- Cabbage with smoked pig leg bone

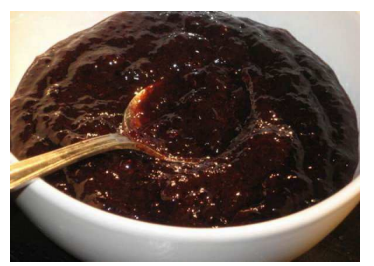

f-Plums jam without sugar

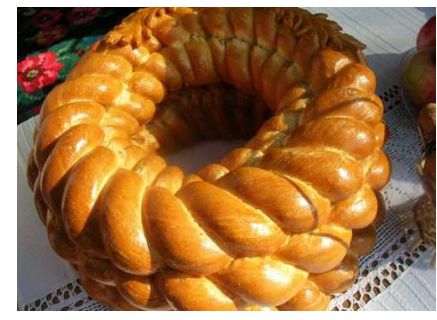

g- Traditional bread

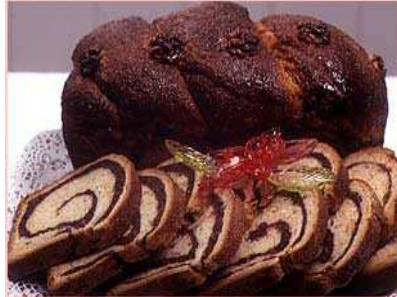

h- Cozonac (sweet baked good)

Fig. 2. Traditional Transylvanian Food (Source: http://delly.garbo.ro/articol/Reteteculinare/14765/varza-a-la-cluj.html,http://www.gustos.ro/retete-culinare/mancare-de-fasole-cu-ciolanafumat.html,http://www.restaurantedelux.ro/ciolan-de-porc-afumat-cu-fasole-sau-varzacalita.html,http://truedelights.ro/2010/04/12/supa-c,u-galusti/

http://sanatate.bzi.ro/magiunul-de-prune,http://www.retete-super.ro/muraturi-pentru-iarna-in-borcan/ http://retete-bucatar.blogspot.ro/2009/07/cozonac-cu-nuca.html)

\section{CONCLUSION}

Transylvania has a regional cuisine, nationally distinct but influenced by other cultures, whose route somehow intersected with the Romanian culture. Transylvanian cuisine may exhibits many local variants, strongly linked with the geographical characteristics and their cultural affinity. In this region, the food reflects both rural and urban culinary habits. The visitors will encounter a great number of local food products, which greatly embellish the travel experience.

\section{REFERENCES}

1. Akeroyd, J. (2006). The Historic Countryside of the Saxon Villages of Southern Transylvania. Art Group Int., Bucharest, Romania

2. Davidson, J. (1982). Man with appetite for excellence. The Glasgow Herald, mar.17

3. Keppler, N. (2011). Taste of Romania, Hippocrene Books, New York.

4. Kovi, P. (1988). Transylvanian Cuisine, Crown Pub 
5. Petrescu, C. (1970). La Paradis General. Miss Romania. Cartea Romaneasca, Bucuresti, Romania

6. Ronay, E. (2004) Palatable Britain, p.201-204. In: Fabry, A.P. Detours: The Art of Uncommon Travel, AuthorHouse, Bloomington, IN, USA.

7. Teodoreanu, Al.O. (2010). Gastronomice. Agora, Bucuresti, Romania

8. Sahleanu, V. (1977). Omul si alimentatia. Ed. Stiintifica si enciclopedica, Bucuresti, Romania

9. Şuta, I. (1995).Universul gastronomic al lumii rurale româneşti din Transilvania, reflectat în cărţile de bucate şi manuscrisele culinare, la mijlocul secolului al xix-lea şi începutul secolului $\mathrm{xx}$, Biblioteca Centrala Universitara Lucian Blaga Cluj-Napoca, www.bcucluj.ro/bibliorev/arhiva/nr17/cultura2.htm

10.http://enciclopediaromaniei.ro/wiki/Transilvania

11.http://www.theguardian.com/lifeandstyle/2003/dec/07/foodanddrink.features2-

12.http://delly.garbo.ro/articol/Retete-culinare/14765/varza-a-la-cluj.html,

13.http://www.gustos.ro/retete-culinare/mancare-de-fasole-cu-ciolan-afumat.html,

14.http://www.restaurantedelux.ro/ciolan-de-porc-afumat-cu-fasole-sau-varza-calita.html,

15.http://truedelights.ro/2010/04/12/supa-c,u-galusti/

16.http://sanatate.bzi.ro/magiunul-de-prune,

17.http://www.retete-super.ro/muraturi-pentru-iarna-in-borcan/

18.http://retete-bucatar.blogspot.ro/2009/07/cozonac-cu-nuca.html 